\title{
Effect of Frequent Testing on Students' Test Anxiety at University Level
}

\author{
Bushra Haleem \\ Ph.D Scholar \\ Institute of Education and Research \\ University of the Punjab \\ scholarbushra@gmail.com
}

\section{Muhammad Saeed}

Former Professor

Institute of Education and Research,

University of the Punjab Lahore, Pakistan.

saeed.ier@pu.edu.pk

\begin{abstract}
This study was designed to find out the effect offrequent Testing on students' test anxiety scores in research method course at university level. The study was expected to predict the effect of worry and emotional scale scores of test anxiety on frequent testing. A quasi-experimental pre-test post-testcontrol group design was used in this study. Two intact groups were selected from the department of science education, Institute of Education and Research, Universityof the Punjab, Lahore. For data collection two instruments i.e. test anxiety Inventory and frequent tests were used. To find out the effect of frequent testing 14 frequent tests were developed by researchers. To measure the students' test anxiety scores, researchers adopted the test anxiety Inventory by Spielberger. The reliability was analyzed through the pilot testing of the instrument. The reliability of the test anxiety inventory was 0.88 . The interventional group was manipulated by frequent testing. The control group was assessed by conventional method. Both groups were compared on test anxiety scores. After analyzing the data, it was observed that both groups experience the same test anxiety in regard to worry and emotional factors. Frequent testing did not effect the test anxiety of students in the research method course. This research will help teachers and senior administration to control students' emotional responses to potentially stressful situations such as exams. Teachers can benefit from widely used strategies for dealing with students' emotions and worries. Stakeholders and evaluators will benefit from the information gathered on how to lessen test anxiety in order to improve the teaching-learning process in the classroom.
\end{abstract}

Keywords: Test, Frequent Testing, Test Anxiety, Worry, Emotion, Scores, University level

Introduction

Teachers recognize the need for improved teaching stra tegies to enhance student achievement and are continually looking for innovative ways that can help students in their success (Palmer, 1974). Test enables educators to have a better understanding of their students. It is a method of determining where students are in the learning process, what may be expected of them, and a generaloverview of

(C) 2021 The Authors, Published by The Women University Multan.

This is an Open Access Article under the Creative Common

Attribution Non-Commercial 4.0
Date of Acceptance: 01 December 2021

Available Online: 15 December 2021 
students' abilities in the tested subject. Testing can help students improve their academic performance if the content is valid and the measurement methods are reliable. It instils trust in the instructor and a good attitude toward the course. A teacher can use tests to identify pupils who have special needs. Some students may require a dditional instruction or guidance during the course.

Tests are becoming more and more important in our daily life. It's unsurprising that tests have emerged as powerful anxiety-inducing stimuli, a nd test anxiety has become a common concern in today's world (Sarason, 1959; Spielberger \& Va gg 1995). Test anxiety is a set of cognitive and emotional responses to the risk of negative consequences as a result of a test or other evaluative event (Zeidner, 1998). Test anxiety's debilitating effect on learning and performance has been thoroughly documented in the research literature. There is a lot of researches on the impact of test anxiety on test performance as measured by total test scores. As a result, tests have become powerful a nxiety stimuli, and test anxiety has become a prevalent problem in our society.

Frequent testing, or the repeated evaluation of subject content, is another technique to improve students' lea rning experiences. Frequent testing refers to examinations that take place over a shorter period of time than the traditional two or three midterms and final exams. It is important to reach an adequate balance between teaching and testing so that both activities are actually performed effectively. Although the duration of time between exams varies among frequent testing studies, all of them aim to improve student achievement by testing students frequently and keeping them alert. Another advantage of frequent testing is that it reduces test anxiety. There is a high correlation between testa nxiety and student achievement. (Cassady \& Johnson, 2002; Deffenbacher, 1980). According to a study, more frequent short testing reduces student anxiety significantly (Dempster, 1992). Furthermore, a ccording to Dustin (1971), student anxiety decrea sed in classes where frequent testing was used.

There are some drawbacks to testing as well. Test a nx iety, or anticipatory anxiety in test-ta king conditions, is a well-known word, and there is a common perception that testing makes students more anxious. There is even a word for anxiety associated to testing called test anxiety. While many test- anxious students are also highly motivated, not all highly motivated students are test- anxious. Anxiety has an impact on a student's ability to learn complex material and achieve a ca demic success (Spielberger, 1966). Poor gra des, dropping out of school, and a genera 1 ina bility to reach realistically a ttainable goals are all possible outcomes of test anxiety (Mandler \& Sarason, 1952). In the literature on frequent testing, there are studies looking at student attitudes after being exposed to frequent testing. Students are asked questions about test anxiety to determine whether there is a relationship between frequent testing and test anxiety.

According to Spielberger (1979), test anxiety is comprised of two main components: worry and emotionality. Worry can include personal concerns about poor test results and theend course or a cademic failure. Fear, panic, tension, and elevated heart and respiration rates are all physiological components of emotionality. In many circumstances, both worry and emotionality can potentially interfere with test performance. Ola dipo and Ogungbamila's (2013) study, on the 
other hand, found opposite results, concluding that test anxiety has no significant relationship with students' a cademic a chievement levels.

Kha lid and Hasan (2009) investigated the rela tionship between test anxiety and academic a chievement in a purposively selected sample of 187 undergraduate students, finding that students with high academic achievement have low test anxiety scores and vice versa. Chapell et al. (2005) studied the relationships between test anxiety and a cademic a chievement in a research study. They looked at a large population of graduate and undergraduate students and found a relationship between test anxiety and academic achievement that was both significa nt and negative. Hancock (2001) looked at how test anxiety and teachers' evaluation strategies affected post-secondary students' achievement and motivation. He revealed statistically significant findings indicating that all students performed poorly and were less ea ger to lea rn, particularly those with a high level of worry. As a result, he came to the conclusion that when test-anxious students are subjected to a highly evaluative assessment atmosphere in their educational institution, they do badly and a reless motivated to perform.

Cassady and Johnson (2002) found out the effect of cognitive test anxiety on students' academic performance and concluded that it has a significant and negative impact on academic performance. Oludipe (2009) investigated how test anxiety impacts students' performance in the sciences, particularly in physics, and found that low test-anxious students scored better on both numerical and nonnumerical tasks in physics than high test-anxious students. Existing test anxiety data in the literature have shown that high test anxiety is common in American school-and college-age populations (e.g., Hill, 1984; Eccles \& Wigfield, 1989), and that it is also the most visible psychological barrier faced by Chinese middleschool and college students (Fan, 2000; Wang, 2003).

Most of the studies focusing on rela tionship and effect of test a nxiety on students' academic a chievement scores and provided conflicting results supporting that frequent testing in the cla ssrooms improves students' a chievement (Gholami \& Moghaddam, 2013; Kling, McCorkle, Miller, \& Reardon, 2005; Leeming, 2002). Frequent tests have been studied for years; however, the research has not yielded convincing results. In fact, many researchers have presented contradictory results. Therefore, it is not clear that the expected results of frequent testing are true or not. Therefore, this proposed research is designed to determine the effective test frequency of evaluating students in the tea ching process in respect to reduce the students' test anxiety in undergraduate education course.

\section{Objective of the Study}

To find out the effect of frequent testing on students' test anxiety scores (worry and emotional) at university level.

\section{Hypotheses}

$\mathrm{H}_{\mathrm{o}} .1$ : There is no significant effect of frequent testing on worry scores of intervention group.

$\mathrm{H}_{\mathrm{o}} .2$ : There is no significant effect of frequent testing on emotional scores of interventional group.

$\mathrm{H}_{\mathrm{o}} .3$ : There is no significant difference between the worry scale scores of test anxiety of control group and experimental group in the pre-test. 
$\mathrm{H}_{\mathrm{o}} .4$ : There is no significant difference between the worry scale scores of test anxiety of control group and experimental group in the posttest.

$\mathrm{H}_{0} .5$ : There is no significant difference between the emotional scale scores of test anxiety of control group and experimental group in the pre-test.

$\mathrm{H}_{\mathrm{o}} .6$ : There is no significant difference between the emotional scale scores of test anxiety of control group and experimental group in the post-test.

\section{Research Methodology}

This experimental research was pla nned to identify the effect of frequent testing on the test anxiety scores of students at university level. A quasi-experimental pre-test post-test control group design wa s used in this study. Two intact groups from department of science education were selected as interventional group and control group. The interventional group wa s manipula ted by frequent testing. The intervention period of the study wa s full semester i.e.16 weeks, three hours per week to meet three credits course requirement. The control group was assessed by conventional method. Both groups were compared on test anxiety scores.

\section{Instrumentation}

For data collection two instruments i.e. test anxiety Inventory and frequent tests were used.

Frequent Tests: The researchers have developed 14 frequent tests, which were administered weekly. Frequent tests consisted of MCQs a nd restricted questions. Each test consisted of 5 MCQs and five marks of restricted questions. 14 frequent tests were developed according to the content delivered by the instructor in a week. To ma intain the difficulty level, tests were ma de according to the table of specification. Items in the tests measured all the levels of cognitive domain presented by Bloom (1956).

Test Anxiety Inventory: The researchers have adopted the test anxiety Inventory by Spielberger (1980) to measure the students' test anxiety scores. The test anxiety in this study is based on a bi-dimensional construct that includes an emotionality and worry scale. The Test Anxiety Inventory consists of 20 selfreport items on a four-point scale ranging from "Almost never" to "Almost always". The validity of the instruments was ensured through the experts' opinion, who were teaching this course. The reliability of the test anxiety inventory was 0.88 . Reliability of two subscales of test anxiety was: Worry scale (.74) and Emotional scale (.73).

\section{Data Collection Procedure}

Before intervention, pretest was taken from both control and interventional groups to collect baseline data for comparison after the intervention. After the collection of baseline data, the treatment was given to the interventional group. The intervention period was 16 weeks, three hours per week. The interventional group was manipulated by frequent testing. Tests were administered weekly for the interventional group. Every week students give tests from previous leamed material which was delivered by the instructor in the previous week. Total 14 tests were a dministered from interventional group. The control group wa s a ssessed by conventional method. Both groups were compared on test anxiety scores as posttest. 


\section{Findings}

To measure the effect of Frequent Testing on Test Anxiety Scores of university students' linea r regression wa s applied. For the comparison of test anxiety scores of both groups independent sample t-test was applied.

Table 1

Regression Coefficient of Frequent Testing on Worry Scores of Test Anxiety

\begin{tabular}{lllllll}
\hline Variable & $\beta 1$ & $B$ & $R^{2}$ & $d f$ & $F$ & Sig \\
\hline Constant & 3.008 & -.097 & .009 & 50 & .463 & .499 \\
Frequent Testing & -.100 & & & & & \\
\hline
\end{tabular}

Table 1 shows a simple linear regression was applied to predict worry scores of test anxiety on frequent testing. An insignificant regression equation was found $\mathrm{F}(1,49)=.463, \mathrm{p}=.000>.499$ with an $\mathrm{R}^{2}$ of .009 . The null hypothesis "there is no significant effect of frequent testing on worry scores of interventional group" is accepted. It is concluded that frequent testing did not effect worry scores of test anxiety. After intervention students experienced test anxiety in rega rd to worry factor.

Table 2

Regression Coefficient of Frequent Testing on emotional Scores of Test Anxiety

\begin{tabular}{lllllll}
\hline Variable & $\beta 1$ & $B$ & $R^{2}$ & $d f$ & $F$ & Sig \\
\hline Constant & 2.641 & -.049 & .002 & 50 & .116 & .735 \\
Frequent Testing & -.053 & & & & & \\
\hline
\end{tabular}

Table 2 shows a simple linear regression was applied to predict emotional scores of test anxiety on frequent testing. An insignificant regression equation was found $\mathrm{F}(1,49)=.116, \mathrm{p}=.000>.735$ with an $\mathrm{R}^{2}$ of .002 . The null hypothesis "there is no significant effect of frequent testing on emotional scale scores of interventional group" is a ccepted. It is concluded that frequent testing did not effect emotional scores of test anxiety. After intervention students experienced test anxiety in rega rd to emotional factor.

Table 3

Independent Sample t-test for Comparison of Worry Scale of Test Anxiety of Control and Experimental Group in the Pre-Test Mean Scores

\begin{tabular}{lcccccc}
\hline Groups & $N$ & Mean & SD & $d f$ & t-value & Sig \\
\hline Control & 28 & 2.20 & .52 & 77 & .23 & .81 \\
Experiment & 51 & 2.17 & .58 & & &
\end{tabular}

Table 3 shows that independent sample t-test was applied to compare the pre-test mean scores of control and experimental group in regard to worry scale of test anxiety. The result revealed that $(t=.23, \mathrm{p}>.81)$ is statistically not significant difference between the worry sca le scores of control group $(\mathrm{M}=2.20, \mathrm{SD}=.52)$ and experimental group $(\mathrm{M}=2.17, \mathrm{SD}=.58)$ in the pretest. So, the null hypothesis "there is no significant difference between the worry sca le scores of test anxiety of control group and experimental group in the pre-test" is accepted. The comparison between control and experimental group did not reveal a significant 
difference. So, it is concluded that students equally experienced the test anxiety in regard to worry scale of control group taught through traditional method and experimental group taught through frequent testing in pretest.

Table 4

Independent Sample t-test for Comparison of Worry Scale of Test Anxiety of Control and Experimental Group in the Post-Test Mean Scores

\begin{tabular}{lcccccc}
\hline Groups & $N$ & Mean & $S D$ & $d f$ & t-value & Sig \\
\hline Control & 28 & 2.08 & .65 & 77 & -1.21 & .22 \\
Experiment & 51 & 2.27 & .63 & & &
\end{tabular}

Table 4 shows that independent sample t-test wa s applied to compare the post-test mean scores of control and experimental group in regard to worry scale of test anxiety. The result revealed that $(t=-1.21, \mathrm{p}>.22)$ is statistically not significant difference between theworry sca le scores of control group $(\mathrm{M}=2.08, \mathrm{SD}=.65)$ and experimental group $(\mathrm{M}=2.27, \mathrm{SD}=.63)$ in the posttest. So, the null hypothesis "there is no significant difference between the worry scale scores of test a nxiety of control group and experimental group in the posttest" is accepted. The comparison between control and experimental group did not reveal a significant difference. So, it is concluded that students equally experienced the test anxiety in regard to worry scale of control group taught through traditional method and experimental group taught through frequent testing in posttest.

Table 5

Independent Sample t-test for Comparison of Emotional Scale of Test Anxiety of Control and Experimental Group in the Pre-Test Mean Scores

\begin{tabular}{lcccccc}
\hline Groups & $N$ & Mean & $S D$ & $d f$ & t-value & Sig \\
\hline Control & 28 & 2.18 & .53 & 77 & .04 & .96 \\
Experiment & 51 & 2.18 & .67 & & &
\end{tabular}

Table 5 shows that independent sample t-test was applied to compare the pre-test mean scores of controls and experimental group in regard to emotional scale of test a nxiety. The result revealed that $(\mathrm{t}=.04, \mathrm{p}>.96)$ is statistically not significant difference between the emotional scale scores of control group $(\mathrm{M}=2.18, \mathrm{SD}=$ $.53)$ and experimental group $(\mathrm{M}=2.18, \mathrm{SD}=.67)$ in the pretest. So, the null hypothesis "there is no significant differencebetween the emotional scale scores of test anxiety of control group and experimental group in the pre-test" is a ccepted. The comparison between con trol and ex perim ental group did not reveal a significant difference. So, it is concluded that students equally experienced the test anxiety in regard to emotional scale of control group taught through tra ditional method and experimental group taught through frequent testing in pretest. 
Table 6

Independent Sample t-test for Comparison of Emotional Scale of Test Anxiety of Control and Experimental Group in the Post-Test Mean Scores

\begin{tabular}{lcccccc}
\hline Groups & $N$ & Mean & $S D$ & $d f$ & t-value & Sig \\
\hline Control & 28 & 2.08 & .68 & 77 & -0.99 & .32 \\
Experiment & 51 & 2.24 & .67 & & &
\end{tabular}

Table 6 shows that independent sample t-test wa s a pplied to compare the post-test mean scores of control and experimental group in regard to emotional scale of test anxiety. The result revealed that $(\mathrm{t}=-0.99, \mathrm{p}>.32)$ is statistically not significant difference between the emotional scale scores of control group $(\mathrm{M}=2.08, \mathrm{SD}=$ $.68)$ and experimental group $(\mathrm{M}=2.24, \mathrm{SD}=.67)$ in the posttest. So, the null hypothesis "there is no significant differencebetween the emotional scale scores of test anxiety of control group and experimental group in the post-test" is a ccepted. The comparison between control and ex perimental group did not reveal a significant difference. So, it is concluded that students equally experienced the test anxiety in regard to emotional scale of control group taught through tra ditional method and experimental group taught through frequent testing in posttest.

\section{Discussion and Conclusion}

The purpose of proposed study was to find out the effect of frequent testing on and test anxiety scores of students in the course of research methods at university level. In this study test anxiety is not affected by frequent testing after treatment in the subject of research methods course. Both control and interventional groups experienced the same test anxiety in regard to worry and emotional scale in the posttest. So, it is concluded that frequent testing did not increase or decrease the test anxiety of students. The findings of this research were supported with the results of Ola dipo and Ogungbamila's (2013). They indicated that test anxiety has no impact on students' a chievement levels.

The findings of this study concluded that the test anxiety of con trol and interventional groups is same. Both groups experienced the same test anxiety. Students who taught with conventional method and those who taught with frequent testing experience the worry and emotional factor same in the pretest and post test scores. According to Nicholson (2009), a study was performed in which he examined the impact of test anxiety on 11 th grade students and discovered a correlation between anxiety and grades. After conducting research on 187 university students with the goal of investigating the connection between test anxiety and academic performance. Khalid and Hasan (2009a) revealed that individuals who have poorer a cademic performance also experience test and vice versa. 


\section{Recommendations}

1. On the basis of results, it is recommended that the identification and treatment of students who are experiencing increased test anxiety is essential if they are to improve their academic performance.

2. Teachers, parents, and educational administrators can help students in effectively managing test anxiety by using cognitive, emotional, and behavioral techniques.

3. Administrators may engage counsellors to talk to students about test anxiety individually, in small groups, and during teaching guidance courses in the classroom.

4. Academic programs in higher education may also focus on teaching students how to control their emotional reactions to potentially stressful events such as testing Faculty can benefit from frequently used techniques for dealing with students' cognitive and emotional anxiety. 


\section{References}

1. Bloom, B. S., Engelhart, M.D., Furst, E. J., Hill, W. H., \& Krathwohl, D. R. (1956). Taxonomy of educational objectives. New York: David McKay Company Inc.

2. Boston, C. (2002). The concept of formative assessment. Practical Assessment Research \& Evaluation, 8(9), 1-6.

3. Cassady, J.C., \& Johnson, R.E. (2002). Cognitive test anx iety and academic performance. Contemporary Educational Psychology, 27, 270-295.

4. Chapell, M.S., Blanding, Z.B., Takahashi, M., Silverstein, M. E., Newman, B., Gubi, A., \&Mccann, N. (2005). Test anxiety and academic performance in undergraduate and graduate students. Journal of Educational Psychology, 97(2), 268-274.

5. Deffenbacher, J. L. (1980). Worry and emotionality in test anxiety. In I. G Sarason (Ed.), Test anxiety: Theory, research, and applications (pp. 111-124). Hillsdale, NJ: Erlbaum

6. Dempster, F. N., \& Farris, R. (1992). The spacing effect: Research and practice. Journal of Research and Developmentin Education, 23(2), 97-101.

7. Dochy, F. (2008). The Edumetric Quality of New Modes of Assessment: Some Issues and Prospects. Assessment, Learning and Judgement in Higher Education. Dordrecht: Springer Netherlands Dempster, F.N. (1991). Synthes is of research on reviews and tests. Educational Leadership, 48,71-76.

8. Fan, X. (2000). An analysis of the results of Test Anxiety Inventory in Hunan area. Chinese Journal of Clinical Psychology, 8(1), 51-52.

9. Gholami, V., \& Moghaddam, M. M. (2013). The effect of weekly quizzes on students' final achievement score. Modern Education and Computer Science, 1,36-41.

10. Hancock, D. R. (2001). Effect of test anxiety and evaluative th reats on students' achievement and motivation. The Journal of Educational Research, 94(5), 284-290.

11. Khalid, R.\& Hasan, S. (2009). Test Anxiety and Low Achievers. Pakistan Joumal of Psychological Research, 24(3-4), 97-114.

12. Kling, N., McCorkle, D., Miller, C., \& Reardon, J. (2005). The impact of testing frequency on student performance in a marketing course. Journal of Education for Business, 81(2), 67-72.

13. Leeming, F.C. (2002). The exam-a-day procedure improves performance in psychology classes. Teaching of Psychology, 29, 210-212.

14. Nichols on, A. M. (2009). Effects of Test Anxiety on Student Achievement (ACT) for College bound Students. Dissertation Abstract International. DAIA-70/07, AAT 3366126.

15. Oladipo, S. E., \& Ogungbamila, A. (2013). Academic level and student's faculty as factors of test anxiety among undergraduates in Nigeria. International Joumal of Development and Sustainability, 2(2), 704-710.

16. Oludipe, B. (2009). Influence of Test Anxiety on Performance levels on Numerical Tasks of Secondary school physics students. Academic Leadership, Online Joumal, $7(4)$.

17. Palmer, E. L. (1974). Frequency of tests and general subject area mastery. Psychological Reports, 35(1), 422.

18. Sarason, S. B., (1959). A study of anxiety and learning. Journal of Abnormal and Social Psychology, 47, 166-173.

19. Spielberger, C. D. (1979). Understandina stress and anxietv. New York: Harper and Row, publishers. Spielberger, C. D., Gonzales, H. P., Taylor, C. J., Anton, W. D., Algaze, B., Ross, G. R., \& Westberry, L. G. (1980). Test anxietv inventorv. (Available from Consulting Psychologists Press, Inc., 3803 E. Bayshore Road, Palo Alto, CA 94303). 